\title{
Insulin-Stimulated Glucose Uptake Involves the Transition of Glucose Transporters to a Caveolae-Rich Fraction within the Plasma Membrane: Implications for Type II Diabetes
}

\author{
Johanna Gustavsson, Santiago Parpal, and Peter Strålfors \\ Department of Cell Biology, Faculty of Health Sciences, University of \\ Linköping, Linköping, Sweden
}

\begin{abstract}
Background: Adipose and muscle tissues express an insulin-sensitive glucose transporter (GLUT4). This transporter has been shown to translocate from intracellular stores to the plasma membrane following insulin stimulation. The molecular mechanisms signalling this event and the details of the translocation pathway remain unknown. In type II diabetes, the cellular transport of glucose in response to insulin is impaired, partly explaining why blood-glucose levels in patients are not lowered by insulin as in normal individuals.

Materials and Methods: Isolated rat epididymal adipocytes were stimulated with insulin and subjected to subcellular fractionation and to measurement of glucose uptake. A caveolae-rich fraction was isolated from the plasma membranes after detergent solubilization and ultracentrifugal floatation in a sucrose gradient. Presence of GLUT4 and caveolin was determined by immunoblotting after SDS-PAGE.
\end{abstract}

Results: In freshly isolated adipocytes, insulin induced a rapid translocation of GLUT4 to the plasma membrane fraction, which was followed by a slower transition of the transporter into a detergent resistant caveolae-rich region of the plasma membrane. The insulin-stimulated appearance of transporters in the caveolae-rich fraction occurred in parallel with enhanced glucose uptake by cells. Treatment with isoproterenol plus adenosine deaminase rapidly inhibited insulin-stimulated glucose transport by $40 \%$, and at the same time GLUT4 disappeared from the caveolae-rich fraction and from plasma membranes as a whole.

Conclusions: Insulin stimulates glucose uptake in adipocytes by rapidly translocating GLUT4 from intracellular stores to the plasma membrane. This is followed by a slower transition of GLUT4 to the caveolae-rich regions of the plasma membrane, where glucose transport appears to take place. These results have implications for an understanding of the defect in glucose transport involved in type II diabetes.

\section{INTRODUCTION}

Insulin lowers the concentration of glucose in the blood; failure to do so causes the rapid onset symptoms of diabetes. Insulin's ability to lower blood glucose levels is partly explained by an increase in the transport of glucose into muscle and adipose tissue. The mechanism involves an insulin-triggered re-localization of glucose transporter type 4 (GLUT4) from intracellular storage sites to the plasma membrane of cells $(1,2)$. Fol-

Address correspondence and reprint requests to: Peter Strålfors, Department of Cell Biology, Faculty of Health Sciences, S-58185 Linkoping, Sweden. lowing homogenization of unstimulated cells, GLUT4 is recovered mainly in the microsomal fraction, but in insulin-stimulated cells up to half of the cellular GLUT4 is recovered in the plasma membrane fraction. The appearance of GLUT4 in the plasma membrane fraction precedes the increase in glucose uptake, suggesting that there might be a delayed activation of GLUT4 (3-5). It has also been found that GLUT4 exists in the plasma membrane in both surface-accessible and -nonaccessible states $(4,6-11)$.

We now report that in rat adipocytes insulin induced a rapid translocation of GLUT4 to the plasma membrane fraction, followed by a slower 
transition of GLUT4 to a detergent-resistant and caveolae-rich fraction within the plasma membrane. Appearance of transporters in this caveolae-rich fraction closely and reversibly paralleled glucose uptake by the cells, suggesting that glucose transport is functional in this fraction of the plasma membrane.

Caveolae form non-clathrin-coated invaginations of the plasma membrane of many cell types and are particularly abundant in adipocytes $(12,13)$. We have previously shown that a phosphatidylinositol-glycan precursor of potential second messengers of insulin is concentrated in the detergent-insoluble caveolae-rich fraction of adipocyte plasma membranes (14).

\section{MATERIALS AND METHODS}

\section{Materials}

2-Deoxy-D-[1- $\left.{ }^{3} \mathrm{H}\right]$ glucose was from Amersham (Amersham, United Kingdom). Porcine insulin from Novo Nordisk (Copenhagen, Denmark), and adenosine deaminase and fatty acid-free bovine serum albumin from Boehringer Mannheim (Mannheim, Germany). Cytochalasin B, Triton $\mathrm{X}-100$ and \pm isoproterenol from Sigma Chemical Co. (St. Louis, MO, U.S.A.). 2-Deoxy-D-glucose and polyclonal rabbit antibodies against insulinregulated glucose transporter (GLUT4) from Calbiochem (U.S.A.), mouse anti-caveolin monoclonal antibodies was from Chemicon International (U.S.A.), and polyclonal rat anti-Na,K-ATPase $\alpha$ 2 subunit fusion protein from Upstate Biotechnology Incorporated (U.S.A.). Suppliers of other materials and equipment are indicated below.

\section{Isolation and Incubation of Adipocytes}

Adipocytes were isolated by collagenase digestion from epididymal fat pads of Sprague Dawley rats (180-250 g; Alab, Stockholm, Sweden) (15). Cells (final concentration $100 \mu$ l packed cell volume $/ \mathrm{ml}$ ) were freshly incubated in Krebs-Ringer solution $(0.12 \mathrm{M} \mathrm{NaCl}, 4.7 \mathrm{mM} \mathrm{KCl}, 2.5 \mathrm{mM}$ $\mathrm{CaCl}_{2}, 1.2 \mathrm{mM} \mathrm{MgSO} 4,1.2 \mathrm{mM} \mathrm{K \textrm {H } _ { 2 }} \mathrm{PO}_{4}$ ) containing $20 \mathrm{mM}$ HEPES, $\mathrm{pH} 7.40,3.5 \%(\mathrm{w} / \mathrm{v})$ bovine serum albumin, $100 \mathrm{nM}$ phenylisopropyladenosine, $0.5 \mathrm{U} / \mathrm{ml}$ adenosine deaminase without or with $0.5 \mathrm{mM} \mathrm{D}$-glucose, at $37^{\circ} \mathrm{C}$ on a shaking water bath (16). In incubations where insulin-stimulated glucose transport was reversed with isoproterenol and adenosine deaminase, cells were stimulated with insulin in the presence of $0.2 \mathrm{mM}$ adenosine instead of phenylisopropyladenosine and without adenosine deaminase until the indicated time point.

\section{Subcellular Fractionation}

Adipocytes were homogenized in $10 \mathrm{mM}$ Tris$\mathrm{HCl}, \mathrm{pH} 7.4,1 \mathrm{mM}$ EDTA, $0.25 \mathrm{M}$ sucrose (with protease inhibitors $10 \mu \mathrm{M}$ leupeptin, $1 \mu \mathrm{M}$ pepstatin, $1 \mu \mathrm{M}$ aprotinin, and $50 \mu \mathrm{M}$ phenylmethylsulfonyl fluoride) using a motordriven Teflon/glass homogenizer at room temperature. Subsequent procedures were carried out at $0-4^{\circ} \mathrm{C}$. A plasma membrane-containing fraction was obtained by centrifugation at $16,000 \times g$ for $20 \mathrm{~min}$ (17). The pellet was resuspended in $10 \mathrm{mM}$ Tris- $\mathrm{HCl}, \mathrm{pH}$ 7.4, $1 \mathrm{mM}$ EDTA. Highly purified plasma membranes were isolated by sucrose density gradient centrifugation $(3,18)$. The microsomal fraction was pelleted by centrifugation of the $16,000 \times g$ supernatant at $160,000 \times g$ (average) for $60 \mathrm{~min}$ (Beckman SW41 rotor).

Aliquots of the plasma membrane fraction in $25 \mathrm{mM}$ HEPES, pH $7.1 / 0.15 \mathrm{M} \mathrm{NaCl}$ were treated with $1 \%(\mathrm{w} / \mathrm{v})$ Triton $\mathrm{X}-100$ for $30 \mathrm{~min}$. To thus solubilized plasma membranes was added solid sucrose to $40 \%$ and layers of 25 and $0 \%$ sucrose were successively layered on top of it. After centrifugation at $200,000 \times g$ (average) for $6.5 \mathrm{hr}$ (Beckman TLS-55 rotor), the material floating at the $25-0 \%$ interface was collected and referred to as the caveolae-rich fraction $(19,20)$.

\section{Immunoblotting}

After SDS-PAGE ( $10 \%$ acrylamide), separated proteins were electrophoretically transferred to a polyvinylidene difluoride blotting membrane (Immobilone-P, Millipore, Marlborough, MA, U.S.A.) in $25 \mathrm{mM}$ Tris, $190 \mathrm{mM}$ glycine, $20 \%$ $(\mathrm{v} / \mathrm{v})$ methanol, $0.05 \%(\mathrm{w} / \mathrm{v})$ sodium dodecyl sulfate, at $50 \mathrm{~mA}$ for $20 \mathrm{hr}$. The wetted membrane was saturated with dry milk, gelatin, or bovine serum albumin with $0.1 \%(\mathrm{w} / \mathrm{v})$ Tween20 . After this blocking procedure the membrane was incubated with anti-glucose transporter-4 antibodies, anti-caveolin monoclonal antibodies, or anti-Na,K-ATPase $\alpha 2$ subunit antibodies in the same solution. Bound antibodies were then detected with horse-radish peroxidase-conjugated anti-IgG, adhering to the ECL protocol and reagents from Amersham. Equal amounts of sample from insulin-treated and nontreated cells were subjected to SDS-PAGE, while the amount 
of protein is not comparable between the different membrane preparations.

\section{Determination of Glucose Transport}

Glucose uptake was determined as 2-deoxy-D$\left[1-{ }^{3} \mathrm{H}\right]$ glucose $(50 \mu \mathrm{M})$ uptake into adipocytes (100 $\mu$ l packed cell volume/ml, final concentration) incubated for $60 \mathrm{sec}$, when glucose transport was interrupted with $25 \mu \mathrm{M}$ cytochalasin B. Cells were immediately separated from incubation medium, collected by 5 -sec centrifugation through dinonylphtalate and frozen. 2-Deoxy-D$\left[1-{ }^{3} \mathrm{H}\right]$ glucose uptake was determined by liquid scintillation counting of cells, after solubilization in sodium dodecyl sulfate, in Ready Gel (Beckman). Nonspecific uptake, determined as the 2-deoxy-D- $\left[1-{ }^{3} \mathrm{H}\right]$ glucose uptake that was not inhibited by cytochalasin B, was subtracted from all measurements.

\section{RESULTS}

Freshly isolated rat adipocytes were incubated either in the presence or absence of $5 \mathrm{nM}$ insulin for $10 \mathrm{~min}$ prior to homogenization and subcellular fractionation. As expected, insulin caused an increase of GLUT4 protein in the plasma membrane (Fig. 1, Lanes 1 and 2) and a decrease in the microsomal fraction (Fig. 1, Lanes 5 and 6). This was followed by enhanced transport of glucose into the cells, with half-maximal transport occurring with about $40 \mathrm{pM}$ insulin (not shown).

A portion of GLUT4 in the plasma membrane fraction was insoluble in the detergent Triton X-100 (Fig. 1, Lanes 3 and 4) and incubation with insulin caused an increase in the amount of GLUT4 in this detergent-insoluble fraction of the plasma membrane (Fig. 1, Lanes 3 and 4). The detergent-insoluble plasma membrane fragments were isolated after ultracentrifugal floatation and characterized as being plasma membrane fragments enriched in caveolae structures. The fraction of GLUT4 in the plasma membrane which we recovered in the detergent-insoluble fraction of unstimulated cells was $5 \pm 0.3 \%$ (mean $\pm \mathrm{SEM} ; n=3$ ). The caveolar-marker protein caveolin also increased in the plasma membrane and in the detergent-insoluble fraction in response to insulin treatment (Fig. 1).

The time courses of insulin's effects on GLUT4 translocation from the microsomal to the plasma membrane, on its transition within the
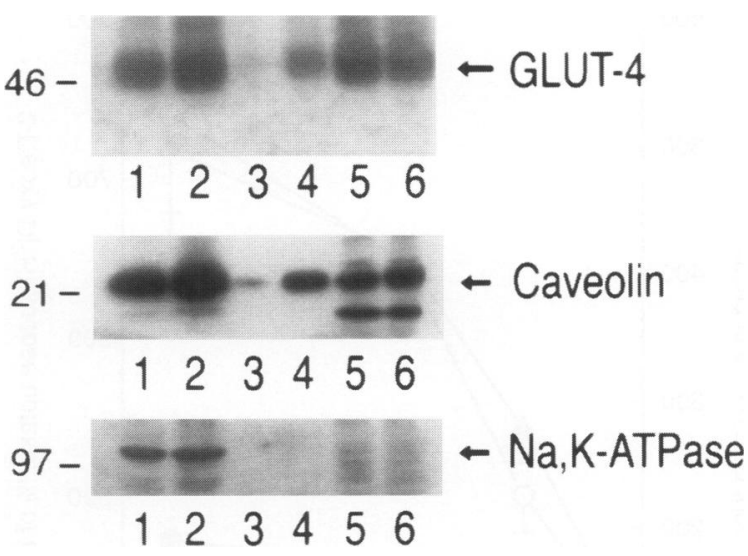

FIG. 1. Effects of insulin on GLUT4 subcellular location.

Rat adipocytes were incubated in the presence or absence of $5 \mathrm{nM}$ insulin for $10 \mathrm{~min}$ and homogenized. Plasma membrane, caveolae, and microsomal fractions were prepared as described in the Materials and Methods. Equal amounts of samples obtained from insulin-treated and nontreated cells were subjected to SDS-PAGE (i.e., the amount of protein is not comparable between the different membrane preparations) and immunoblotted for GLUT4, caveolin, or $\mathrm{Na}, \mathrm{K}$-ATPase $\alpha 2$ subunit. (Lanes 1 and 2) Plasma membranes. (Lanes 3 and 4) Caveolae. (Lanes 5 and 6) Microsomal fraction. In Lanes 1, 3, and 5, cells were incubated without insulin; in Lanes 2, 4, and 6, with insulin. The positions of molecular mass markers (Rainbow, Amersham) are indicated: ovalbumin, $46 \mathrm{kD}$; phosphorylase, $97 \mathrm{kD}$, trypsin inhibitor, $21 \mathrm{kD}$.

plasma membrane, and on the stimulation of glucose uptake were examined. Following addition of insulin, the amount of GLUT4 rapidly decreased in the microsomal fraction, and in parallel there was a rapid increase $\left(t_{1 / 2}: \mathrm{ca} .3 \mathrm{~min}\right)$ in the amount of GLUT4 in the plasma membranes (Fig. 2). In the detergent-insoluble fraction of the plasma membranes, the amount of GLUT4 increased more slowly $\left(t_{1 / 2}:\right.$ ca. $\left.7 \mathrm{~min}\right)$. The increase in glucose uptake coincided with the accumulation of GLUT4 in the detergent-insoluble fraction of the plasma membrane, but not with the considerably more rapid appearance of transporters in the plasma membrane as a whole (Fig. 2). The level of GLUT4 remained elevated in this detergent-insoluble fraction of the plasma membrane (as well as in the plasma membrane as a whole) for at least 20 min (the longest time period studied).

The stimulatory effect of insulin on glucose transport is counteracted by addition of isopro- 

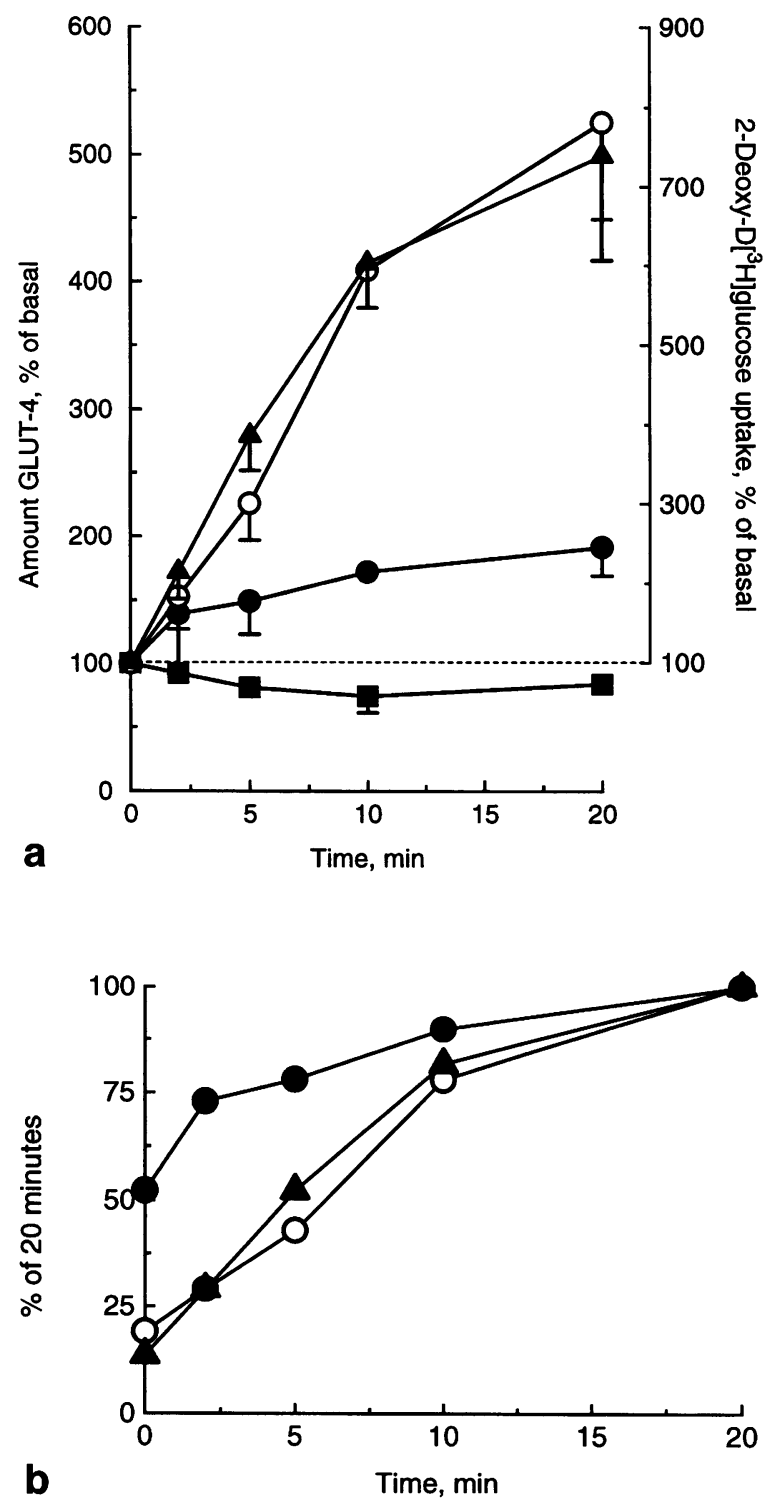

FIG. 2. Time course of the effects of insulin stimulation on GLUT4 subcellular localization and on glucose transport

Adipocytes were sampled before insulin addition at the indicated time points after the addition of $5 \mathrm{nM}$ insulin. Subcellular fractions were isolated as in Fig. 1 and the amount of GLUT4 determined after SDSPAGE and immunoblotting. Quantitative evaluation of immunoblots was done by densitometric scanning (Pharmacia-LKB Ultroscan) of films and integration of areas under peaks. Glucose transport was determined as 2-deoxy-D- $\left[1-{ }^{3} \mathrm{H}\right]$ glucose uptake. (a) Results of GLUT4 quantitation mean \pm SEM $(n=3-12$ separate experiments) and for glucose uptake (mean \pm SEM, $n=3$ separate experiments) are expressed as a percentage of nonstimulated controls (error bar is shown only where this value is greater than the graph symbol). (b) Data replotted as a percentage of the respective maximal $(20 \mathrm{~min})$ value. Plasma membranes; $\bigcirc$, caveolae; $\boldsymbol{\square}$, microsomal fraction; $\boldsymbol{\Delta}$, glucose transport.

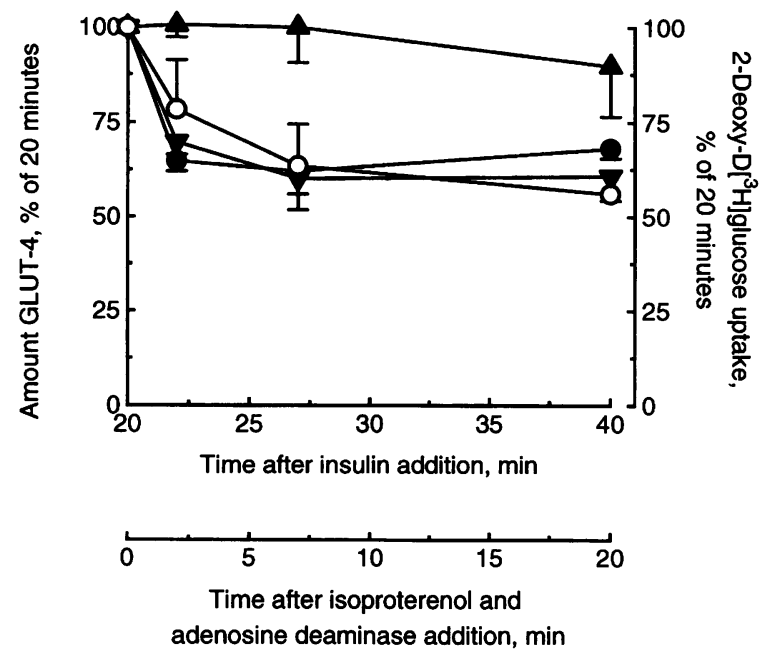

FIG. 3. Time course for isoproterenol/adenosine deaminase inhibition of insulin-stimulated GLUT4 translocation and glucose transport

Adipocytes were stimulated with $5 \mathrm{nM}$ insulin for 20 min, at which point $1 \mu \mathrm{M}$ isoproterenol and 0.5 $\mathrm{U} / \mathrm{ml}$ adenosine deaminase were added. Cells were then sampled at the indicated time points. Subcellular fractionation, immunoblotting, the amount of GLUT4, and glucose transport were determined as in the legend to Fig. 2. Results of GLUT4 quantitation mean $\pm \operatorname{SEM}$ ( $n=3$ separate experiments) and for glucose uptake (mean $\pm \mathrm{SEM}, n=3$ separate experiments) are expressed as percent of maximally insulin-stimulated controls ( $5 \mathrm{nM}$ insulin for $20 \mathrm{~min}$ ) (error bar is shown only where this value is greater than the graph symbol). 0 , Plasma membranes; $O$, caveolae; $\nabla, 2$-deoxy-D- $\left[1-{ }^{3} \mathrm{H}\right]$ glucose uptake; $\boldsymbol{\Delta}$, 2 -deoxy-D- $\left[1-{ }^{3} \mathrm{H}\right]$ glucose uptake in control cells without isoproterenol or adenosine deaminase.

terenol in combination with adenosine removal by adenosine deaminase (10). The effects of this treatment on the distribution of GLUT4 was determined in cells that had been maximally stimulated with $5 \mathrm{nM}$ insulin for $20 \mathrm{~min}$. The combination of isoproterenol and adenosine deaminase rapidly reversed insulin-stimulated glucose transport by $40 \%$. In parallel, GLUT4 disappeared from the detergent-insoluble fraction and from the plasma membrane as a whole (Fig. 3).

The detergent-insoluble fraction of the plasma membrane was isolated from the purified plasma membranes and characterized. It had several characterstics of isolated caveolae (21), as demonstrated by: (i) its insolubility in Triton $\mathrm{X}-100$; (ii) its floatation during density-gradient ultracentrifugation; (iii) the presence of the caveolar-marker protein caveolin (Fig. 1), which is known to be abundant in adipocytes' caveolae 
$(12,13)$; and (iv) the absence of Na,K-ATPase, a plasma membrane protein not present in caveolae (Fig. 1). In a previous study by our group, this fraction had been further described (14), showing that in nonstimulated adipocytes the caveolar-marker protein caveolin was 8-fold enriched compared with plasma membranes, and it contained less than $10 \%$ of the plasma membrane protein with a different protein pattern after SDS-PAGE.

\section{DISCUSSION}

The findings reported here demonstrate that GLUT4 is translocated to the plasma membrane in response to insulin and then to specialized regions of the plasma membrane, which may represent caveolae, where glucose uptake appears to take place. Although the detergent-resistant fraction of the plasma membrane may not necessarily correspond to caveolae alone, it should represent functional and most likely also physical microdomains of the plasma membrane. These are exciting findings in light of our recent localization of a phosphatidylinositol glycan, which may be involved in insulin signaling to the same caveolae-rich fraction (14). It is pertinent to point out that biochemical studies of GLUT4 localization, commonly involving solubilization with nonionic detergent and centrifugal removal of insoluble material prior to GLUT4 quantitation, may exclude GLUT4 present in the detergent-insoluble fraction from quantitation. There has been some question as to whether a detergent-resistant fraction of the plasma membrane corresponds to morphologically defined caveolae (21). Recently, however, it was carefully demonstrated that the proteins, including glycosylphosphatidylinositol-linked proteins, contained in caveolae isolated as a detergent-insoluble fraction are also found in caveolae isolated by a procedure totally avoiding detergents (22).

Kandror et al. (13) recently demonstrated that intracellular vesicles containing GLUT4 were not associated with caveolin. These investigators, however, did not examine either plasma membranes or plasma membrane-caveolae structures for colocalization of GLUT4 and caveolin, and it is therefore not possible to compare their findings with ours. Their findings were, however, contradicted by Scherer et al. (12) who also showed that insulin stimulated a transient increase of GLUT4 in a caveolin containing fraction prepared from whole 3T3-Ll cells. Our results do not show any evidence of such transient localization of GLUT4 in the caveolae-fraction during insulin stimulation, possibly because we have used freshly isolated adipocytes and isolated caveolae from purified plasma membranes.

Our findings indicate that the following events occur during insulin stimulation of glucose uptake: (i) a rapid change of the steady-state distribution of GLUT4 from intracellular loci to the plasma membrane; (ii) a slower transition of GLUT4 into a specialized region of the plasma membrane, which may correspond to caveolae; and (iii) enhanced glucose uptake. This provides a mechanistic explanation for the long-standing discrepancy between the rapid increase of GLUT4 in the plasma membrane and the slower increase of glucose uptake (3-5). A number of investigations have indicated that the glucose transporter exists in two states in the plasma membrane: one which is surface accessible and one occluded $(4,6-11)$. Our findings now indicate that the surface-accessible transporters in the plasma membrane may correspond to transporters localized to the detergent-insoluble fraction and furthermore that these correspond to actively transporting GLUT4. In addition, the results suggest that in response to insulin GLUT4 rapidly appears at the plasma membrane in a nontransporting state, likely corresponding to occluded transporters that have not yet reached the detergent-insoluble region.

\section{REFERENCES}

1. Cushman SW, Wardzala LJ. (1980) Potential mechanism of insulin action on glucose transport in the isolated rat adipose cell. $J$. Biol. Chem. 255: 4758-4762.

2. Suzuki K, Kono T. (1980) Evidence that insulin causes translocation of glucose transport activity to the plasma membrane from an intracellular storage site. Proc. Natl. Acad. Sci. U.S.A. 77: 2542-2545.

3. Karnieli E, Zarnowski M, Hissin PJ, Simpson IA, Salans LB, Cushman SW. (1981) Insulinstimulated translocation of glucose transport systems in the isolated rat adipose cell. $J$. Biol. Chem. 256: 4772-4777.

4. Satoh S, Nishimura H, Clark A, et al. (1993) Use of bis-mannitol photolabel to elucidate insulin-regulated GLUT-4 subcellular trafficking kinetics in rat adipose cells. Evidence that exocytosis is a critical site of hormone action. J. Biol. Chem. 268: 17820-17829. 
5. Gibbs EM, Lienhard GE, Gould GW. (1988) Insulin-induced translocation of glucose transporters to the plasma membrane precedes full stimulation of hexose transport. Biochemistry 27: 6681-6685.

6. Joost HG, Weber TM, Cushman SW. (1988) Qualitative and quantitative comparison of glucose transport activity and glucose transporter concentration in plasma membranes from basal and insulin-stimulated rat adipose cells. Biochem. J. 249: 155-161.

7. Lange K, Brandt U. (1990) Insulin-responsive glucose transporters are concentrated in a cell surface-derived membrane fraction of 3T3-L1 adipocytes. FEBS Lett. 261: 459-463.

8. Clark AE, Holman GD, Kozka IJ. (1991) Determination of the rates of appearance and loss of glucose transporters at the cell surface of rat adipose cells. Biochem. J. 278: 235-241.

9. Smith RM, Charron MJ, Shah N, Lodish HF, Jarett L. (1991) Immunoelectron microscopic demonstration of insulin-stimulated translocation of glucose transporters to the plasma membrane of isolated rat adipocytes and masking of the carboxyl-terminal epitope of intracellular GLUT4. Proc. Natl. Acad. Sci. U.S.A. 88: 6893-6897.

10. Vannucci SJ, Nishimura H, Satoh S, Cushman SW, Holman GD, Simpson IA. (1992) Cell surface accessibility of GLUT4 glucose transporters in insulin-stimulated rat adipose cells, modulation by isoprenaline and adenosine. Biochem. J. 288: 325-330.

11. Holman GD, Leggio LL, Cushman SW. (1994) Insulin-stimulated GLUT4 glucose transporter recycling. J. Biol. Chem. 269: 17516-17524.

12. Scherer PE, Lisanti MP, Baldini G, Sargiacomo M, Mastick CC, Lodish HF. (1994) Induction of caveolin during adipogenesis and association of GLUT4 with cavolin-rich vesicles. J. Cell Biol. 127: 1233-1243.

13. Kandror KV, Stephens JM, Pilch PF. (1995) Expression and compartmentalisation of caveolin in adipose cells: co-ordinate regulation with and structural segregation from GLUT4. J. Cell Biol. 129: 999-1006.

14. Parpal S, Gustavsson J, Strålfors P. (1995) Isolation of phosphooligosaccharide/phosphoinositol glycan from caveolae and from cytosol of insulin-stimulated cells. J. Cell Biol. 131: 125-135.

15. Strålfors $\mathrm{P}$, Honnor RC. (1989) Insulin-induced dephosphorylation of hormone-sensitive lipase, correlation with lipolysis and cAMP-dependent protein kinase activity. Eur. J. Biochem. 182: 379-385.

16. Strålfors P. (1988) Insulin stimulation of glucose uptake can be mediated by diacylglycerol in adipocytes. Nature (Lond.) 335: 554556.

17. Oka Y, Czech M. (1984) Photoaffinity labelling of insulin-sensitive hexose transporters in intact rat adipocytes, direct evidence that latent transporters become exposed to the extracellular space in response to insulin. $J$. Biol. Chem. 259: 8125-8133.

18. McKeel DW, Jarett L. (1970) Preparation and characterisation of a plasma membrane fraction from isolated fat cells. J. Cell Biol. 44: 417-432.

19. Chang WJ, Ying YS, Rothberg KG, et al. (1994) Purification and characterisation of smooth muscle cell caveolae. J. Cell Biol. 126: 127-138.

20. Sargiacomo $M$, Sudol $M$, Tang ZL, Lisanti MP. (1993) Signal transducing molecules and glycosyl-phosphatidylinositol-linked proteins form a caveolin-rich insoluble complex in MDCK cells. J. Cell Biol. 122: 789-807.

21. Parton GP, Simons K. (1995) Digging into caveolae. Science 269: 1398-1399.

22. Smart EJ, Ying YS, Mineo C, Anderson RGW. (1995) A detergent-free method for purifying caveolae membrane from tissue culture cells. Proc. Natl. Acad. Sci. U.S.A. 92: 10104-10108. 